\title{
Reproductive biology and range extension for Mobula kuhlii cf. eregoodootenkee
}

\author{
Matt K. Broadhurst ${ }^{1,2, *}$, Betty J. L. Laglbauer ${ }^{3}$, Katherine B. Burgess ${ }^{4}$, \\ Melinda A. Coleman ${ }^{1}$ \\ ${ }^{1}$ NSW Department of Primary Industries, National Marine Science Centre, PO Box 4321, Coffs Harbour, NSW, Australia \\ ${ }^{2}$ Marine and Estuarine Ecology Unit, School of Biological Sciences, University of Queensland, St Lucia, QLD, Australia \\ ${ }^{3}$ Department of Oceanography and Fisheries, University of the Azores, Horta, Faial, Portugal \\ ${ }^{4}$ School of Biomedical Sciences, University of Queensland, St Lucia, QLD, 4072, Australia
}

\begin{abstract}
Mobulids have been poorly studied, but most are listed by the International Union for the Conservation of Nature as Near Threatened or of greater concern. Here we fill critical knowledge gaps surrounding reproduction for Mobula kuhlii cf. eregoodootenkee caught at $29^{\circ} \mathrm{S}-$ $200 \mathrm{~km}$ south of their proposed range - off eastern Australia by bather-protection gillnets deployed for 6 mo from December 2016. M. kuhlii cf. eregoodootenkee was the second most abundant netted species (all adults: $\mathrm{n}=63$ ), with catches peaking in April. There was no sexual segregation, but females (disc width [DW]: 92.5 to $130.0 \mathrm{~cm}$, mean $\pm \mathrm{SD} 112.8 \pm 7.8 \mathrm{~cm}$ ) were significantly larger than males $(99.0$ to $123.0 \mathrm{~cm}, 109.4 \pm 6.3 \mathrm{~cm})$. Of those caught, 45 died $(71 \%$ mortality), of which 20 females and 11 males were assessed for reproduction. Nine females were pre-ovulatory and non-gravid with 7 to 23 oocytes in their left ovary, while 11 had 14 to 40 ovarian oocytes and 1 embryo (DW: 7.0 to $21.2 \mathrm{~cm}$ ) in their left uterus. The diameter of the largest ovarian follicle in gravid females was not correlated with embryo size, indicating ovulation may not occur immediately after parturition. The development of the largest embryo (DW: $21 \mathrm{~cm}$ ) suggests parturition occurs well above this size. Males had calcified claspers and exhibited large variation in their testes weights, which might imply seasonal fluctuation in sperm production. In addition to extending the distribution of the species and increasing maximum DW to $130 \mathrm{~cm}$, the data provide further evidence of the low reproductive output of $M$. kuhlii cf. eregoodootenkee, and a need for their effective management.
\end{abstract}

KEY WORDS: Elasmobranch $\cdot$ Embryo $\cdot$ Gillnet $\cdot$ Mobula $\cdot$ Reproduction

\section{INTRODUCTION}

The family Mobulidae (mantas and devilrays) is distributed throughout tropical and warm-temperate seas and historically has included 2 poorly studied genera: Manta and Mobula, comprising 2 and 9 species, respectively (Notarbartolo-di-Sciara 1987, White et al. 2006). Recently, the entire family was updated to the singular Mobula with 8 species (White et al. 2017). Of these, 5 ( $M$. alfredi, $M$. birostris, M. mobular, M. tarapacana and $M$. thurstoni) are cosmopolitan, while the remaining 3 ( $M$. hypostoma, $M$. kuhlii

\footnotetext{
${ }^{*}$ Corresponding author: matt.broadhurst@dpi.nsw.gov.au
}

and $M$. munkiana) are endemic to the western Atlantic, Indo-West Pacific and eastern tropical Pacific oceans, respectively.

Despite this taxonomic revision, further investigation is required to ascertain phylogeny. Specifically, based on divergence between mitochondrial genomes and nuclear exon data in the lesser devilray $M$. kuhlii and the pygmy devilray $M$. eregoodootenkee falling within the range of intraspecific variation, the latter was reclassified as M. kuhlii (White et al. 2017). But there remain important morphological differences (e.g. among gill plates and body colouration)

() The authors 2018. Open Access under Creative Commons by Attribution Licence. Use, distribution and reproduction are unrestricted. Authors and original publication must be credited. 
which warrant research to confirm whether $M$. eregoodootenkee is a valid species (Misty Paig-Tran \& Summers 2013, Notarbartolo di Sciara et al. 2017). Here we refer to the species complex as M. kuhlii cf. eregoodootenkee.

Nearly all mobulids, including $M$. eregoodootenkee, are listed as Near Threatened or of greater concern throughout their ranges ( $M$. kuhlii is Data Deficient; IUCN 2017). Although the species are poorly studied, these broad classifications reflect very low reproductive output (uniparity and potentially biennial or triennial parturition) and vulnerability to various fishing gears (Couturier et al. 2012, Lawson et al. 2017). Mobulids frequently are caught in gillnets and are targeted in developing countries for domestically consumed meat, or for their gill plates that typically are exported to China for use in traditional medicines (Couturier et al. 2012, Lawson et al. 2017). Some mobulids, including M. kuhlii cf. eregoodootenkee, have been harvested for many years throughout their Indo-Pacific distributions and there are concerns about over-exploitation (White et al. 2006). A lack of data describing key life-history parameters, including reproduction, precludes informed population management, other than precautionary recommendations.

$M$. kuhlii cf. eregoodootenkee may also be incidentally caught in tuna and purse-seine fisheries off northern Australia (hypothesized to be the limit of its southern range; Compagno \& Last 1999, Lawson et al. 2017), since congenerics are encountered in similar industrial fisheries elsewhere (Mas et al. 2015, Francis \& Jones 2017), but the species is not selected by any inshore commercial or recreational fishing gears. Nevertheless, like M. kuhlii off South Africa (Dudley \& Cliff 1993) M. kuhlii cf. eregoodootenkee is likely vulnerable to capture in bather-protection gillnets, which were first introduced to protect bathers against sharks in Queensland about 55 yr ago (Sumpton et al. 2011). Catches in these gillnets typically are grouped as Mobula spp. (Sumpton et al. 2011). Similar gillnets have also been deployed off Sydney, New

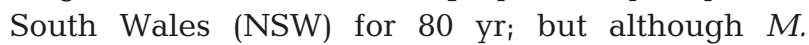
birostris is infrequently caught, the fished area does not encompass the distribution of M. kuhlii cf. eregoodootenkee (e.g. Krogh \& Reid 1996).

Recently, in response to a cluster of shark-human interactions, bather-protection gillnets were deployed off northern NSW during a 6-mo trial and in an area not previously subjected to any fishing effort by these or similar gears. M. kuhlii cf. eregoodootenkee was the second most abundant netted species $(23 \%$ of the total catch). Considering a lack of data describ- ing reproduction in mobulids, but the implication of life histories characterized by a combination of biological factors that could render the family susceptible to overfishing, our main aim here was to provide the first quantitative assessment of reproduction in M. kuhlii cf. eregoodootenkee.

\section{MATERIALS AND METHODS}

This study used specimens caught as bycatch in 5 bather-protection gillnets deployed at fixed locations during 6 mo from 8 December 2016 off northern NSW $\left(28.77^{\circ} \mathrm{S}, 153.60^{\circ} \mathrm{E}\right.$ to $29.10^{\circ} \mathrm{S} ; 153.44^{\circ} \mathrm{E}$; Fig. 1). Each gillnet was $150 \mathrm{~m}$ long and 4 or $6 \mathrm{~m}$ deep and comprised $600 \mathrm{~mm}$ knotted mesh (inside stretched mesh opening) made from either 1.8 or $2.1 \mathrm{~mm}$ diameter $(\varnothing)$ braided polyethylene twine attached to $20 \mathrm{~mm} \varnothing$ polypropylene floatlines and $8 \mathrm{~mm} \varnothing$ polyamide foot ropes at a hanging ratio of 0.67 . All nets were secured parallel to the 5 beaches in 5 to $13 \mathrm{~m}$ of water with $30 \mathrm{~kg}$ anchors at each end and had 5 surface floats $(\sim 300 \mathrm{~mm} \varnothing)$ attached to $\sim 2 \mathrm{~m}$ ropes (16 $\mathrm{mm} \varnothing$ twisted polypropylene) between the surface and the floatline, so the foot rope was always off the bottom. Attempts were made to fish the nets continuously, while checking and clearing them daily, and always with an onboard scientific observer trained in marine-vertebrate identification.

During gillnet checks (with the intervening period defined as the 'soaktime'), the water depth and temperature were recorded and any Mobula kuhlii cf. eregoodootenkee were untangled from the netting. The entanglement side was noted as east (seaward) or west (landward), and individuals were assessed for status (alive or dead), sexed, measured for disc width (DW) to the nearest $1 \mathrm{~mm}$, and immediately released if alive. Badly decomposed specimens were discarded at sea. All other dead specimens were transported to a laboratory and stored in a freezer at $-20^{\circ} \mathrm{C}$ prior to assessment. Each collected specimen was sexed, weighed (to the nearest $10 \mathrm{~g}$ ) and measured (DW) prior to dissection and removal of reproductive organs.

Data collected for males included the clasper length (inner) and stage of calcification, and the mass of the heaviest testis. For females, the weight of the functional left ovary and width of the oviducal gland were recorded; the number of ovarian follicles was counted; and the diameter of the largest follicle (DOLF) was measured. Uteri were measured for width before being dissected and any embryos 
removed. Embryos were sexed, weighed, measured (DW) and qualitatively described. All reproductive weights and lengths were to the nearest $1 \mathrm{~g}$ and $1 \mathrm{~mm}$, respectively.

Size-frequency distributions of males and females caught were compared by a 2-sample KolmogorovSmirnov test. A chi-squared goodness of fit test was used to examine the hypothesis of an equal sex ratio among total catches of $M$. kuhlii cf. eregoodootenkee. Regression analyses were used to test the hypotheses of (1) no effect of soaktime on catches; and (2) no relationships between embryo DW and either the DOLF of the mother or days after first gravid capture (defined as days from the date the first gravid female was caught).

\section{RESULTS}

The 5 gillnets were fished at the same locations for between 144 and 167 days and nights over the 6-mo trial, and only removed for short periods during poor weather. Between 79 and 144 gillnet checks were done per month. Water depths during gillnet checks were between 5.0 and $13.0 \mathrm{~m}$ (mean $\pm \mathrm{SD} 9.0 \pm 1.7 \mathrm{~m}$ ) while the average monthly sea-surface temperatures ranged between $19.8 \pm 1.6$ and $24.6 \pm 1.1^{\circ} \mathrm{C}$ (Table 1$)$.

Catches in the nets comprised 275 individuals across $>20$ species, but $83 \%$ of the total were elasmobranchs, including the Australian cownose ray Rhinoptera neglecta ( $\mathrm{n}=81$ ), Mobula kuhlii cf. eregoodootenkee $(n=63)$, white spotted eagle ray Aetobatus ocellatus $(\mathrm{n}=38)$, great hammerhead Sphyrna mokarran $(\mathrm{n}=24)$ and common blacktip shark Carcharhinus limbatus $(\mathrm{n}=12)$. Three other mobulids were caught (all up to $3.0 \mathrm{~m} \mathrm{DW}$ ); one of these was identified as the reef manta ray $M$. alfredi, and 2 remained unidentified (all 3 escaped alive). Most of the M. kuhlii cf. eregoodootenkee were caught at Lennox Beach and Evans Head (Table 1, Fig. 1). Time of capture could not be accurately determined for all specimens, but at least 9 M. kuhlii cf. eregoodootenkee were caught during daylight (between 07:00 and 17:00h); based on
Table 1. Monthly data on catches of Mobula kuhlii cf. eregoodootenkee in bather-protection nets off northern New South Wales, Australia, between December 2016 and May 2017: mean $( \pm$ SD) water temperature, total number of individuals caught, sex ratio, and number of individuals sampled. na: not applicable

\begin{tabular}{|lcccc|}
\hline Month & $\begin{array}{c}\text { Water } \\
\text { temperature } \\
\left({ }^{\circ} \mathrm{C}\right)\end{array}$ & $\begin{array}{c}\text { No. } \\
\text { caught }\end{array}$ & $\begin{array}{c}\text { Sex ratio } \\
\text { caught } \\
(\mathrm{M}: \mathrm{F})\end{array}$ & $\begin{array}{c}\text { No. } \\
\text { sampled }\end{array}$ \\
\hline December & $19.8(1.5)$ & 0 & na & 0 \\
January & $22.0(1.3)$ & 7 & $6: 1$ & 0 \\
February & $22.7(1.7)$ & 5 & $1.5: 1$ & 3 \\
March & $24.6(1.1)$ & 5 & $0: 5$ & 2 \\
April & $22.0(0.9)$ & 34 & $1: 2.1$ & 22 \\
May & $20.8(0.7)$ & 12 & $5: 1$ & 4 \\
\hline
\end{tabular}

their condition in the net during subsequent daily checks, many of the others (at least 35) were assumed to have been caught overnight.

During net checks, $28 \mathrm{M}$. kuhlii cf. eregoodootenkee were solitarily entangled, but the remaining 35 a) Ballina region
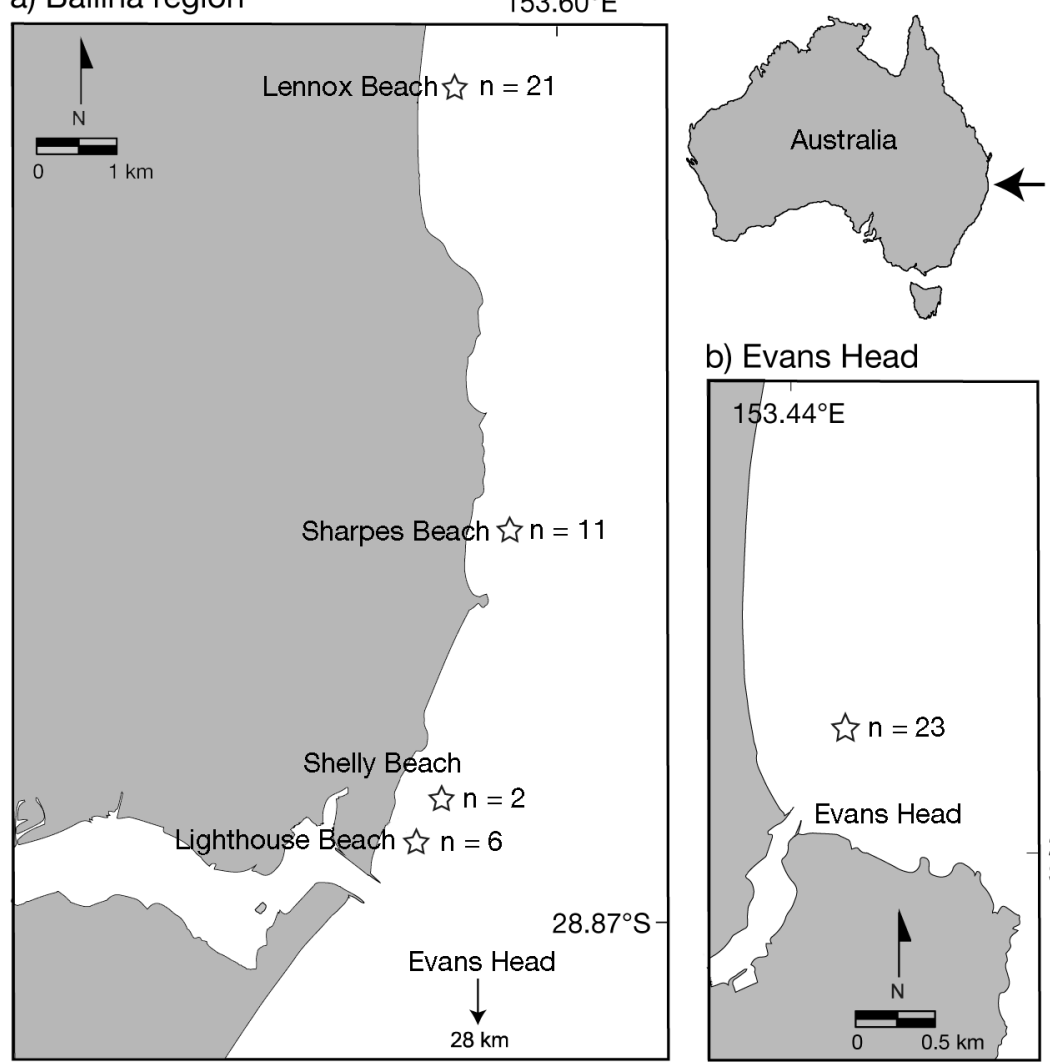

b) Evans Head

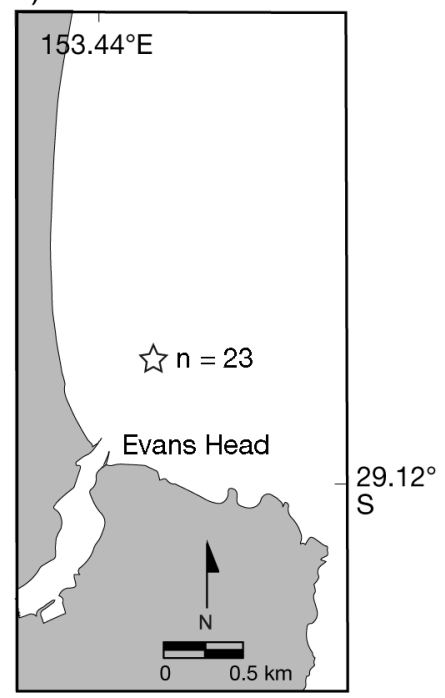

Fig. 1. Location of sites at (a) Ballina and (b) Evans Head in northern New South Wales, Australia (inset), where Mobula kuhlii cf. eregoodootenkee were caught in stationary bather-protection gillnets between December 2016 and May 2017. Open stars mark the locations of nets, and the number of individuals caught is given alongside 


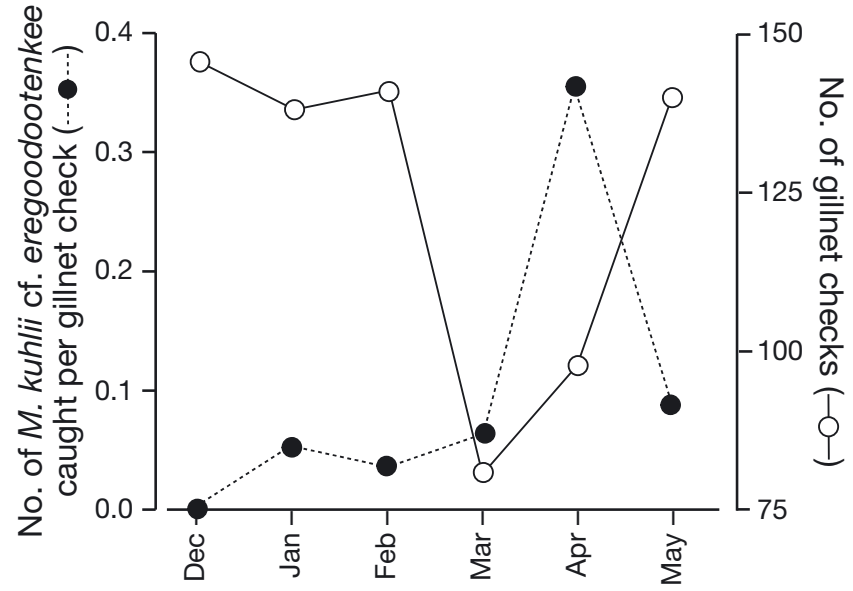

Fig. 2. Numbers of checks on bather-protection gillnets off northern New South Wales, Australia ( $n=5$ gillnets; see Fig. 1) (solid line) and numbers of Mobula kuhlii cf. eregoodootenkee caught per gillnet check (dashed line) for each month from December 2016 to May 2017

were simultaneously caught in groups of 2 to 6 individuals, and often spread across $\sim 75 \mathrm{~m}$ of the net length. There was no significant relationship between the numbers of $M$. kuhlii cf. eregoodootenkee caught and gillnet soaktime (range 1.1 to $145.0 \mathrm{~h}$, mean \pm SD $24.5 \pm 24.7 \mathrm{~h}$ ) and so catches were standardised to number per gillnet check (linear regression, p > 0.05; Fig. 2). No M. kuhlii cf. eregoodootenkee were caught during December (Fig. 2). There were similar relative abundances among the remaining months, except for a considerable peak in April (Fig. 2).

The total catch of $M$. kuhlii cf. eregoodootenkee comprised 31 females (DW: 92.5 to $130.0 \mathrm{~cm}$, mean $\pm \mathrm{SD} 112.7 \pm 7.7 \mathrm{~cm}$ ), 29 males (DW, excluding 2 unmeasured individuals: 99.0 to $123.0 \mathrm{~cm}, 109.4 \pm$ $6.3 \mathrm{~cm}$ ) and 3 individuals that were unsexed (owing to decomposition) (Table 1, Fig. 3). Monthly sex ratios varied, but the pooled ratio was not significantly different from parity $\left(\chi^{2}=0.02, \mathrm{p}>0.05\right.$; Table 1). Females were significantly larger than males (Kolmogorov-Smirnov test, $\mathrm{p}<0.01$; Fig. 3). Irrespective of sex, where net entanglement side could be ascertained, most specimens (25 of 34) caught in the 4 gillnets off Ballina were entangled on the eastern (seaward) side, while those at Evans Head were more commonly entangled on the western side (14 of 22).

Of those caught, $45 \mathrm{M}$. kuhlii cf. eregoodootenkee died in the gillnets ( $71 \%$ mortality). Of these fatalities, 20 females (DW: 92.5 to $118.5 \mathrm{~cm}, 113.1 \pm 5.6 \mathrm{~cm}$; weight: 10.8 to $24.8 \mathrm{~kg}, 18.9 \pm 2.9 \mathrm{~kg}$ ) and 11 males (DW: 99.0 to $109.0 \mathrm{~cm}, 104.6 \pm 3.3 \mathrm{~cm}$; weight: 13.0

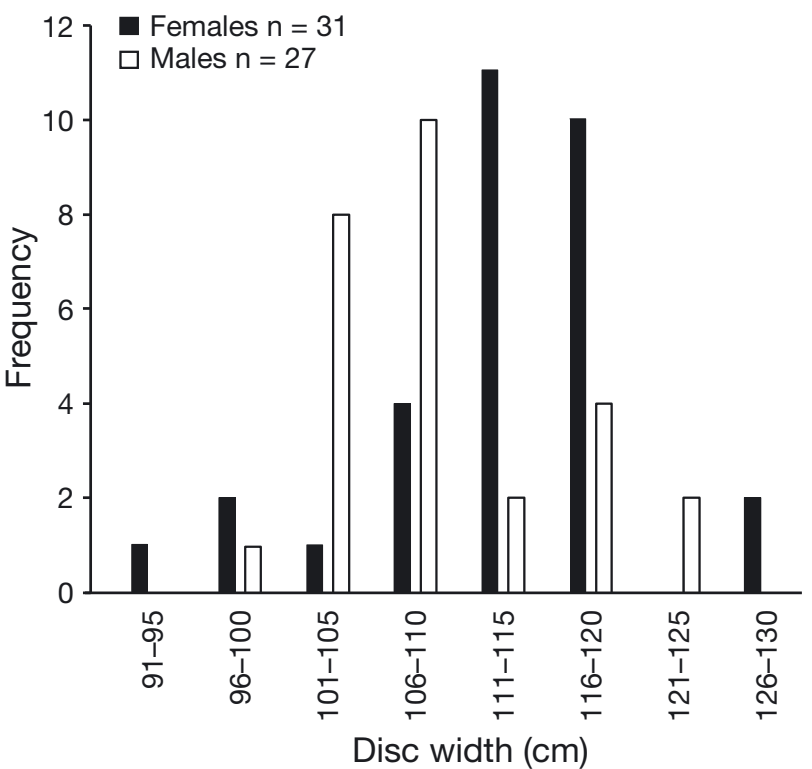

Fig. 3. Disc width $(\mathrm{cm})$ frequency distributions $(5 \mathrm{~cm}$ size classes) of female and male Mobula kuhlii cf. eregoodootenkee caught in bather-protection gillnets off northern New South Wales, Australia, between December 2016 and May 2017

to $16.5 \mathrm{~kg}, 14.6 \pm 1.2 \mathrm{~kg}$ ) were retained for necropsies and reproductive assessment (Table 1). Based on ovarian and uterine development, 9 females were mature but non-gravid and classed as pre-ovulatory (DW: 92.5 to $118.5 \mathrm{~cm}$ ), while 11 were gravid (DW: 111.0 to $117.5 \mathrm{~cm}$ ) (Fig. 4).

Five of the largest pre-ovulatory females had left uterus widths that were close to, or encompassed, the sizes of those that were gravid (>6.8 cm; Fig. 4a). Both pre-ovulatory and gravid females had similarsized DOLFs (between 7 and 40 oocytes in the functional left ovary). Three of the pre-ovulatory specimens had relatively large DOLFs of 2.3 to $3.0 \mathrm{~cm}$, while only one gravid female had a DOLF of $3.0 \mathrm{~cm}$ (Fig. 4b). Four of the gravid females had oviducal glands considerably wider than those in the preovulatory females (Fig. 4c).

The 11 gravid females each had a single embryo ( 7 males and 4 females) in the left uterus, with all but one (the largest) orientated in the same direction as the mother (rostrum forwards) with their pectoral fins folded ventrally and in varying stages of development (Table 2, Fig. 5). All embryos except the largest were a uniform pink colour. Each of these embryos had a visible notochord and a tail mostly slightly longer than its DW, and relatively much longer than that of its mother (Table 2, Fig. 5). The largest embryo (21.2 cm DW) still had a lot of yolk present and its skin was still thin enough to render the brain visible across the skin (Table 2). These characteristics 

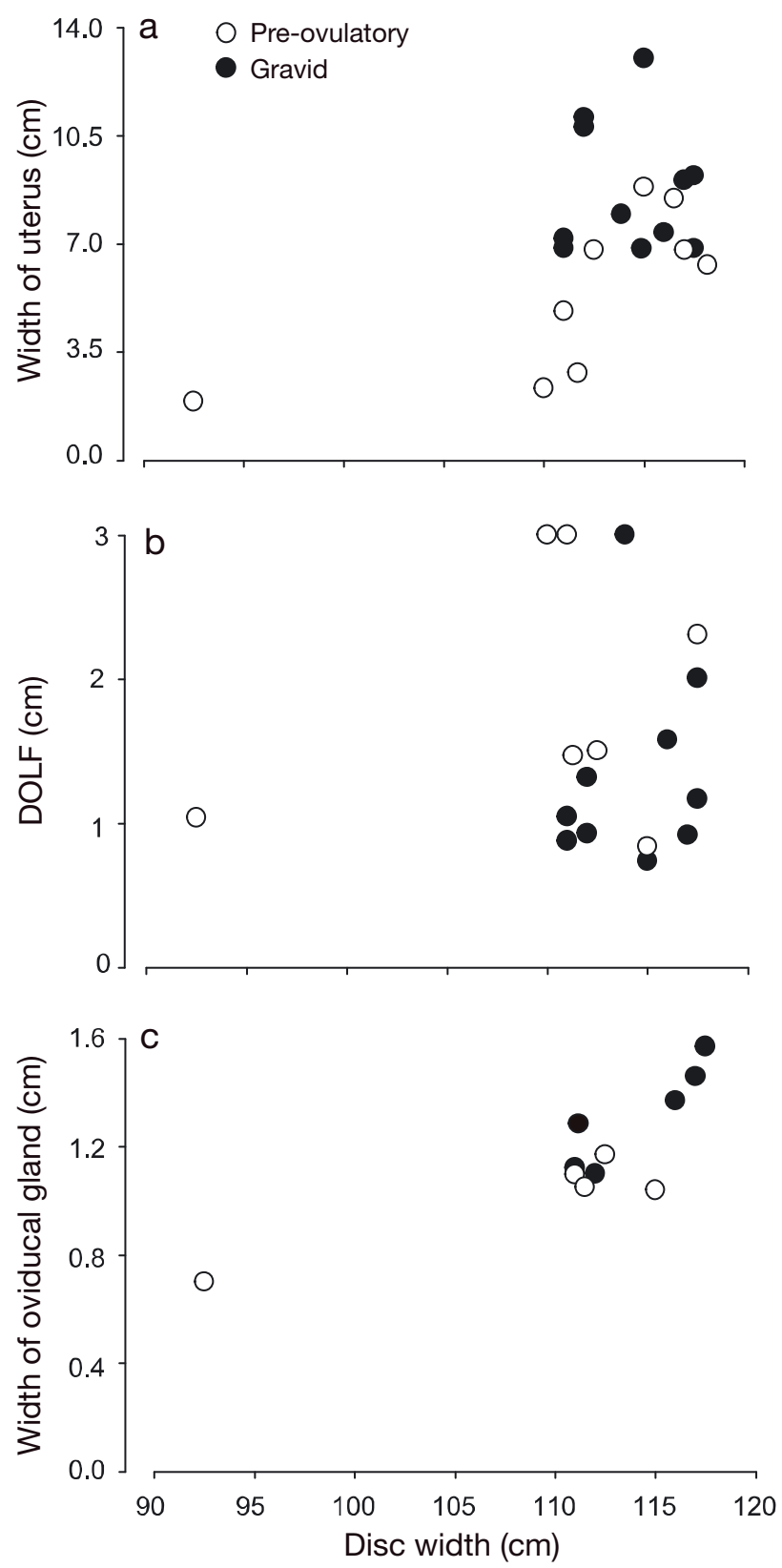

Fig. 4. Relationships between disc width and (a) width of uterus, (b) diameter of the largest ovarian follicle (DOLF), and (c) width of oviducal gland for (O) pre-ovulatory ( $\mathrm{n}=5$ to 9) and (@) gravid ( $\mathrm{n}=6$ to 11) Mobula kuhlii $\mathrm{cf}$. eregoodootenkee caught in bather-protection gillnets off northern New South Wales, Australia, between December 2016 and May 2017

implied it was not at term. There was no significant linear relationship between embryo DW and the DOLF of the mother ( $p>0.05$; Fig. 6a). There was a significant linear relationship between embryo size and days after first gravid capture ( $p<0.05$; Fig. $6 b)$.

The 11 males were all mature with calcified claspers (length 9.2 to $11.0 \mathrm{~cm}$; Fig. 7a). There was no evidence of seminal fluid. In 3 animals, either testes exhibited mild autolysis, but the weights of the heavier ranged between 13 and $48 \mathrm{~g}$ (Fig. 7b).

\section{DISCUSSION}

The data presented here represent the first quantitative assessment of Mobula kuhlii cf. eregoodootenkee reproduction and complement previous limited and opportunistic observations describing conservative life-history parameters in this species complex (Compagno \& Last 1999, White et al. 2006, Notarbartolo di Sciara et al. 2017). Equally important, the catches from the fixed and mostly continuously deployed gillnets facilitate quantifying variation in regional spatio-temporal abundances of M. kuhlii cf. eregoodootenkee to infer broader patterns, albeit with some caveats.

Fishing-gear selectivity is an important consideration when assessing catches as indices of relative abundances. Like all gillnets, those assessed here would be expected to have some form of modal selection curve (Hamley 1975) that probably encompassed the largest $M$. kuhlii cf. eregoodootenkee in the area, since many larger animals, including 3 very large mobulids (up to $3.0 \mathrm{~m} \mathrm{DW}$ ), were also caught. These observed sizes extend the assumed maximum size for the species from $\sim 119 \mathrm{~cm}$ (White et al. 2006) to $130 \mathrm{~cm}$ DW. Gillnet selectivity means it is likely that smaller M. kuhlii cf. eregoodootenkee) (e.g. $<90 \mathrm{~cm}$ DW) would have avoided capture. Rohner et al. (2017) observed similar size selection (minimum $108 \mathrm{~cm} \mathrm{DW}$ ) for mobulids (e.g. M. thurstoni) in a commercial Philippines drift gillnet (mesh size $\sim 500$ to $800 \mathrm{~mm}$ ) fishery. Such selectivity means that while there were no differences in the sex ratio of adult M. kuhlii cf. eregoodootenkee off northern NSW, possible size-based segregation, or departures from sexual parity among smaller size classes cannot be ruled out.

Irrespective of size selectivity it is clear that the southern limit of the species' range can be extended to $29^{\circ} \mathrm{S}$; well beyond the limit of $\sim 9^{\circ} \mathrm{S}$ proposed for M. eregoodootenkee by Compagno \& Last (1999) and the limit of $27^{\circ} \mathrm{S}$ proposed more recently by Bray (2017). Mobula kuhlii cf. eregoodootenkee is predominantly a tropical species and it remains to be confirmed whether the southern extension is a regular event or a reflection of record high water temperatures recorded off eastern Australia during 2015 to 2016 (Hughes et al. 2017). Certainly the greatest abundance of $M$. kuhlii cf. eregoodootenkee ob- 
Table 2. Gravid Mobula kuhlii cf. eregoodootenkee females and their embryos caught in gillnets deployed between December 2016 and May 2017 off northern New South Wales $\left(29^{\circ} \mathrm{S}\right)$, showing date of capture and disc width (DW, cm) of females, and the sex, DW, and total and yolk weights $(\mathrm{g})$ of embryos, together with a qualitative assessment of their stage of development. '-' indicates that the weight of the yolk was not determined or the yolk was not collected

\begin{tabular}{|c|c|c|c|c|c|c|}
\hline $\begin{array}{l}\text { Date of } \\
\text { capture }\end{array}$ & $\begin{array}{c}\text { Gravid } \\
\text { DW }\end{array}$ & Sex & $\begin{array}{l}\text { DW } \\
(\mathrm{cm})\end{array}$ & $\begin{array}{l}\text { Total } \\
\text { Teight } \\
\text { (g) }\end{array}$ & $\begin{array}{l}\text { Yolk } \\
\text { weight } \\
\text { (g) }\end{array}$ & Qualitative descriptions \\
\hline 17 March & 115.0 & Male & 8.5 & 7.9 & - & $\begin{array}{l}\text { Abundant histotroph present in the uterus when dissected. Large yolk. } \\
\text { The skin was very thin, fragile, and pink and cartilaginous structures } \\
\text { (spine) were easily visible. Eyes were protruding, pink and not well } \\
\text { developed. Very long tail relative to disc length. }\end{array}$ \\
\hline 10 April & 112.0 & Male & 14.3 & 40.1 & 0.93 & $\begin{array}{l}\text { Histotroph present upon dissection of the uterus. Yolk was present and } \\
\text { still attached. Protruding eyes, uniform pink colour, notochord and } \\
\text { developing cartilaginous structures visible across thin skin. No evidence of } \\
\text { darker/black patterns. Very long tail }(16.5 \mathrm{~cm}) \text {. }\end{array}$ \\
\hline 10 April & 112.0 & Female & 16.8 & 80.1 & 0.53 & $\begin{array}{l}\text { Histotroph present upon dissection of the uterus. Yolk was present and } \\
\text { still attached. Protruding eyes, uniform pink colour, notochord and } \\
\text { developing cartilaginous structures visible across thin skin. No evidence of } \\
\text { darker/black patterns. The body cavity appeared to be of a darker pinkish } \\
\text { tint, likely due to the presence of developing organs. Very long tail }(18.9 \mathrm{~cm}) \text {. }\end{array}$ \\
\hline 10 April & 117.0 & Female & 16.4 & 70.0 & 0.37 & $\begin{array}{l}\text { Yolk was present and still attached. Protruding eyes, uniform pink colour, } \\
\text { notochord and developing cartilaginous structures visible across thin skin. } \\
\text { No evidence of darker/black patterns. The body cavity appeared to be of a } \\
\text { darker pinkish tint, likely due to the presence of developing organs. Very } \\
\text { long tail }(20.5 \mathrm{~cm}) \text {. }\end{array}$ \\
\hline 10 April & 117.5 & Female & 7.0 & 8.0 & - & $\begin{array}{l}\text { Large yolk sack attached to the embryo. The skin was very thin, fragile, } \\
\text { pink and developing cartilaginous structures (especially the spine) were } \\
\text { easily visible. Eyes were protruding, pink and not well developed. Very } \\
\text { long tail ( } 6.2 \mathrm{~cm} \text {; Fig. 5a). }\end{array}$ \\
\hline 16 April & 116.0 & Male & 16.0 & 82.4 & - & $\begin{array}{l}\text { Yolk was present and still attached. Protruding eyes, uniform pink colour, } \\
\text { notochord and developing cartilaginous structures visible across thin skin. } \\
\text { No evidence of darker/black patterns. Very long tail relative to disc length. }\end{array}$ \\
\hline 26 April & 111.0 & Male & 18.6 & 118 & - & $\begin{array}{l}\text { Yolk was present and still attached. Protruding eyes, uniform pink colour, } \\
\text { notochord and developing cartilaginous structures visible across thin skin. } \\
\text { No evidence of darker/black patterns. Very long tail relative to disc length. }\end{array}$ \\
\hline 26 April & 113.6 & Male & 16.0 & 61.4 & 0.41 & $\begin{array}{l}\text { Histotroph present upon dissection of the uterus. Protruding eyes, uniform } \\
\text { pink colour, notochord visible and white across thin skin. No evidence of } \\
\text { darker/black patterns. The body cavity appeared to be of a darker pinkish } \\
\text { tint, likely due to the presence of developing organs. Very long tail }(17.0 \mathrm{~cm}) \text {. }\end{array}$ \\
\hline 26 April & 117.5 & Male & 17.0 & 76.3 & 0.43 & $\begin{array}{l}\text { Yolk was present and still attached. Protruding eyes, uniform pink colour, } \\
\text { notochord and developing cartilaginous structures visible across thin skin. } \\
\text { No evidence of darker/black patterns. Very long tail }(19.0 \mathrm{~cm}) \text {. }\end{array}$ \\
\hline 27 April & 111.0 & Female & 15.7 & 71.5 & - & $\begin{array}{l}\text { Yolk was present and still attached. Protruding eyes, uniform pink colour, } \\
\text { notochord and developing cartilaginous structures visible across thin skin. } \\
\text { No evidence of darker/black patterns. Very long tail relative to disc } \\
\text { length. }\end{array}$ \\
\hline 24 May & 115.0 & Male & 21.2 & 146.0 & 0.28 & $\begin{array}{l}\text { Thicker skin than other embryos, lower level of transparency on the } \\
\text { ventral side, although the brain and notochord were white and easily } \\
\text { visible across the skin on the dorsal side. Dark pigmentation in a band } \\
\text { pattern extended from the nasal extremity of the eyes along the dorsal } \\
\text { edge of the cephalic fins (Fig. 5b). Black colouration around eyes, which } \\
\text { were less protruding than in other embryos sampled. White patch towards } \\
\text { the centre and base of the mouth (above tooth plate). The pectoral fins and } \\
\text { the body showed pinkish-to-white colouration on the ventral and dorsal } \\
\text { side and on the ventral side below the head. Lateral-line canals were } \\
\text { visible on the dorsal side. Yolk was still present, indicating the embryo } \\
\text { was not at term. This embryo was the only one encountered facing } \\
\text { downwards in the uterus. Very long tail }(25.0 \mathrm{~cm}) \text {. }\end{array}$ \\
\hline
\end{tabular}



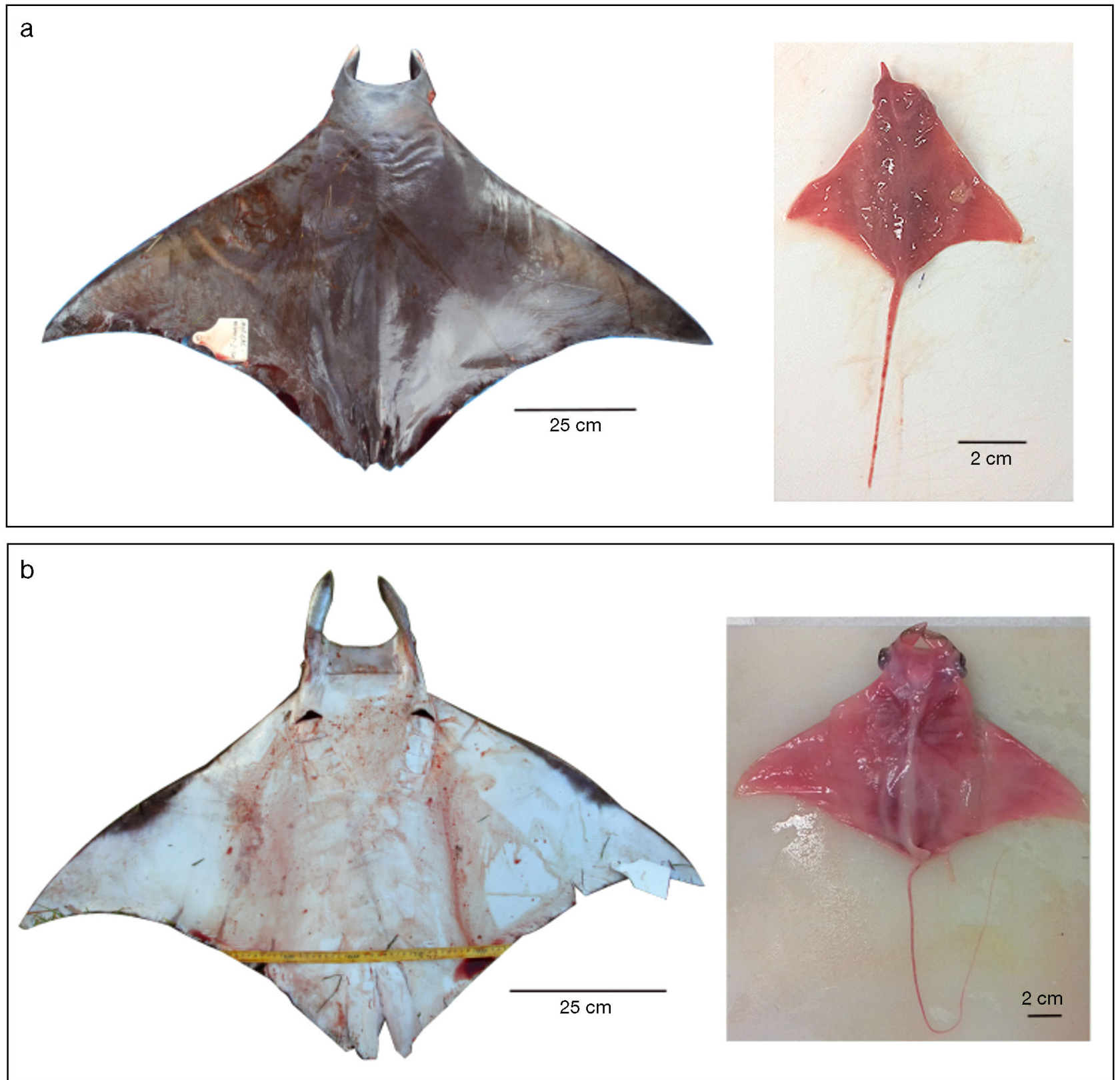

Fig. 5. The (a) smallest (7.0 cm disc width [DW]) and (b) largest (21.2 cm DW) embryos of Mobula kuhlii cf. eregoodootenkee and their gravid mothers (117.5 and 115.0 DW, respectively) caught in bather-protection gillnets off northern New South Wales, Australia, between December 2016 and May 2017. Note the differences in relative tail lengths between adults and embryos

served in the present study was during April, following the warmest water temperatures ever recorded during the summer months off the eastern Australian coast. These catches compare to only 11 unspecified Mobula spp. (but $82 \mathrm{M}$. birostris) caught in 14 batherprotection gillnets fished year-round off southern Queensland ( 26 to $\left.28^{\circ} \mathrm{S}\right)$ between 1992 and 2008 (Sumpton et al. 2011).

The specific location of $M$. kuhlii cf. eregoodootenkee in the gillnets relative to beaches provides information on their possible behaviour prior to capture. More than $55 \%$ of the animals were entangled in groups of 2 to 6 individuals. It is well established that larger mobulids ( $M$. birostris and $M$. alfredi) typically are solitary, except for periodic aggregations that can be driven by feeding (Anderson et al. 2011), cleaning (Rohner et al. 2013) or reproductive opportunities (Yano et al. 1999). Aggregations among smaller individuals might not only similarly facilitate feeding, but also 


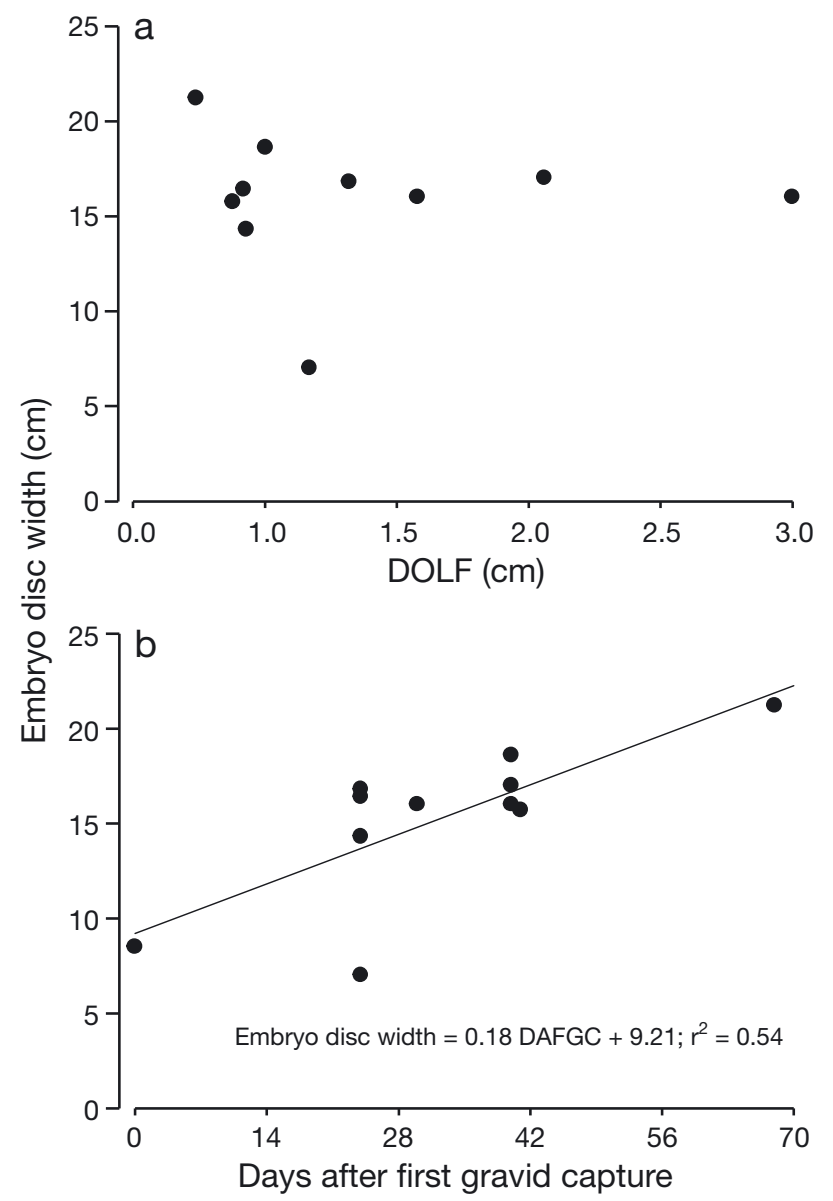

Fig. 6. Relationships between embryo disc width from gravid Mobula kuhlii cf. eregoodootenkee caught in bather-protection gillnets off northern New South Wales, Australia, between December 2016 and May 2017 and (a) the diameter of the largest ovarian follicle (DOLF) and (b) days after first gravid capture (DAFGC (Day 0 = 17 Mar 2017: the first date of capture of a gravid female; see Table 2). The line in (b) indicates a significant regression $(p<0.05)$

be an advantageous anti-predator strategy (the main predator being large sharks; reviewed by Couturier et al. 2012).

Presumably, many of the M. kuhlii cf. eregoodootenkee caught here were schooling which, at a fine scale, might indicate short-term movements in relation to local topography. The majority of $M$. kuhlii $\mathrm{cf}$. eregoodootenkee caught had full to moderately full stomachs (with some clearly containing teleosts; K. Burgess et al. unpubl. data). While most individuals found in the nets at Ballina were caught on the westward side (i.e. traveling landward), many of those at Evans Head (the only location opposite to a river mouth) were caught on the opposite side (traveling seaward). Possibly, these latter individuals were utilizing the river mouth for food and were then
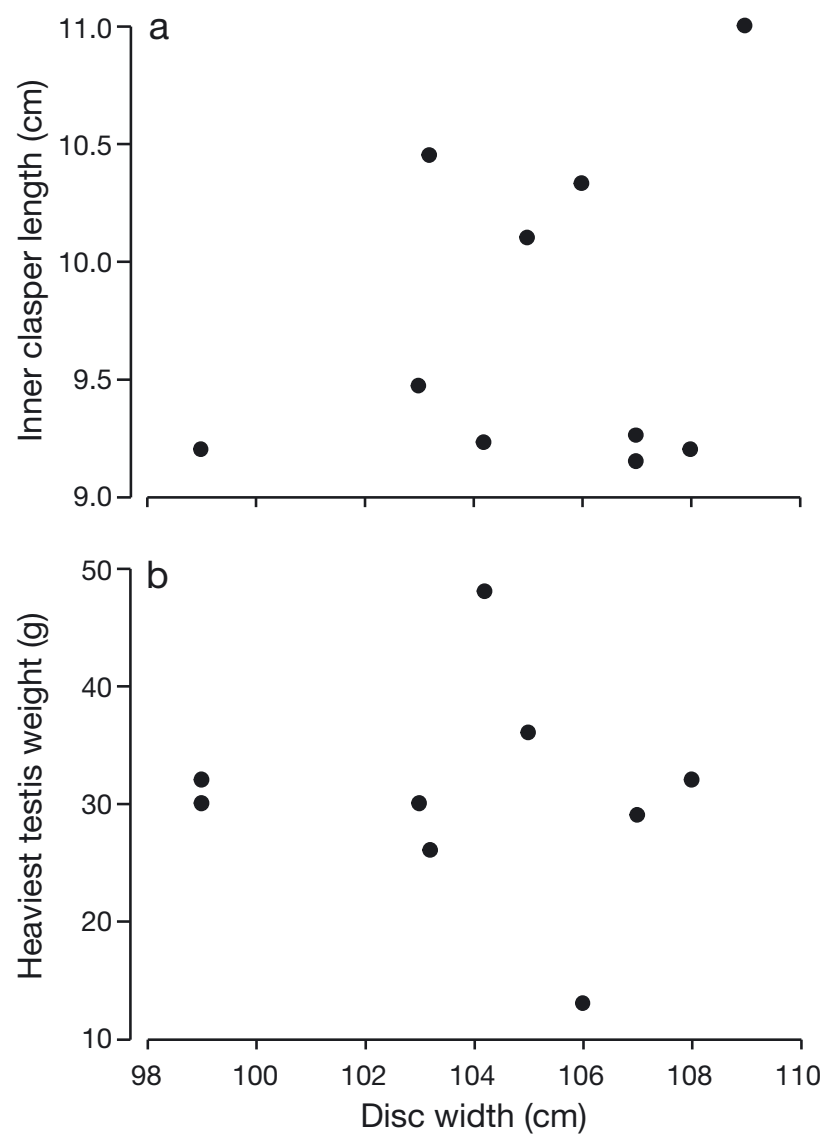

Fig. 7. Relationships between disc width $(\mathrm{cm})$ of adult male Mobula kuhlii cf. eregoodootenkee caught in bather-protection gillnets off northern New South Wales, Australia, between December 2016 and May 2017 and (a) length of inner clasper $(\mathrm{cm})$ and $(\mathrm{b})$ weight of heaviest testis $(\mathrm{g})$

caught moving back out to sea; although in the absence of additional data, such a hypothesis is quite speculative.

At a broader level, the observed clustering of mature M. kuhlii cf. eregoodootenkee and especially pre-ovulatory and gravid females, might be indicative of a reproductive aggregation off northern NSW, although the lack of data precludes estimating when ovulation occurs or if the species remains in the area. All specimens were adults, with the smallest females and males measuring 92.5 and $99.0 \mathrm{~cm}(\mathrm{DW})$, respectively. No previous estimates of size at maturity are available for females, but White et al. (2006) proposed male maturity in $M$. kuhlii at 115 to $119 \mathrm{~cm}$ DW. The results here provide evidence that both sexes mature at considerably smaller sizes.

All females had either embryos or were developing ovarian follicles, which in some cases were quite large (e.g. DOLF $=3.0 \mathrm{~cm}$ ). Some females 
also had wide oviducal glands, and it is possible some of these females were approaching ovulation, although it is important to note that a DOLF of $3.0 \mathrm{~cm}$ was also recorded in 1 gravid female (with a $16.0 \mathrm{~cm}$ DW embryo). The smallest female $(92.5 \mathrm{~cm}$ DW) had 7 oocytes up to $1.5 \mathrm{~cm}$ in diameter, and might have been undergoing its first ovulation. Males showed large variation in testes weight, which might either be associated with a seasonal fluctuation in sperm production, or indicate that some were more successful at mating than others. These observations are not sufficient to propose the timing of copulation.

There was no evidence of a relationship between the development of ovarian follicles and embryos, and so birth probably is not annual. During a study involving photo identification of $M$. alfredi-a closely related species to $M$. kuhlii cf. eregoodootenkee-off Mozambique, Marshall \& Bennett (2010) proposed a predominantly biennial reproductive periodicity, but some individuals nevertheless were observed to be pregnant during consecutive years. Such observations imply that $M$. alfredi has an annual ovulatory cycle which, when considered with the data here, suggest some diversity in reproductive periodicities within Mobulidae.

The gestation period for M. kuhlii cf. eregoodootenkee remains cryptic. We observed a difference in size of $14 \mathrm{~cm}$ DW between the smallest and largest embryos over $68 \mathrm{~d}$. M. birostris neonates are born at about one-third of the DW of an adult (e.g. Marshall \& Bennett 2010) and Compagno \& Last (1999) proposed a birth size of $31 \mathrm{~cm}$ DW for $M$. kuhlii, which would also be a similar relative proportion of adult size. The largest embryo here $(21.2 \mathrm{~cm}$ DW) was clearly still developing, with considerable yolk still present and many unformed features. So, perhaps parturition would be towards the Austral late spring/ summer.

This study reiterates that like many other mobulids, M. kuhlii cf. eregoodootenkee has a very low reproductive output and, owing to aggregations in seasonally productive habitats, is clearly vulnerable to capture. While fishing effort for this species in Australia is mostly limited to bather-protection gillnets used in Queensland, and total catches are likely to be low, the species has a high discard mortality, from 71 (this study) to $89 \%$ (Sumpton et al. 2011). Assuming a similar response in other gillnet fisheries throughout their tropical distribution, along with their confirmed low fecundity and variable reproductive periodicity, populations are unlikely to be able to withstand sustained fishing pressure.
Acknowledgements. This study was funded by the NSW Department of Primary Industries and had animal ethics approval (NSW DPI ACEC ref. no. 08-06). We thank the skippers and crews of the FV 'Wahoo' and FV 'Haven Star' for their assistance at sea; Sean Blake, Isabelle Thiebaud, Steve Kay, Euan Provost, and Andrew Colefax for assistance with processing the specimens; and Giuseppe Notarbartolo di Sciara and an anonymous referee for their constructive comments during manuscript review.

\section{LITERATURE CITED}

Anderson RC, Adam MS, Goes JI (2011) From monsoons to mantas: seasonal distribution of Manta alfredi in the Maldives. Fish Oceanogr 20:104-113

* Bray DJ (2017) Mobula kuhlii. In: Fishes of Australia. http:// fishesofaustralia.net.au/home/species/2036 (accessed on 2 August 2017)

Compagno LJV, Last PR (1999) Mobulidae. In: Carpenter KE, Niem VH (eds) FAO species identification guide for fishery purposes. The living marine resources of the Western Central Pacific, Vol. 3: batoid fishes, chimaeras and bony fishes part 1 (Elopidae to Linophrynidae). Food and Agriculture Organization of the United Nations, Rome, p 1524-1529

Couturier LIE, Marshall AD, Jaine FRA, Kashiwagi T and others (2012) Biology, ecology and conservation of the Mobulidae. J Fish Biol 80:1075-1119

* Dudley SFJ, Cliff G (1993) Some effects of shark nets in the Natal nearshore environment. Environ Biol Fishes 36: 243-255

Francis MP, Jones EG (2017) Movement, depth distribution and survival of spinetail devilrays (Mobula japanica) tagged and released form purse-seine catches in New Zealand. Aquatic Conserv: Mar Freshw Ecosyst 27: 219-236

Hamley JM (1975) Review of gillnet selectivity. J Fish Res Board Can 32:1943-1969

* Hughes TP, Kerry JT, Álvarez-Noriega M, Álvarez-Romero JG and others (2017) Global warming and recurrent mass bleaching of corals. Nature 543:373-377

IUCN (International Union for the Conservation of Nature) (2017) The IUCN Red List of Threatened Species. www. iucnredlist.org (accessed in August 2017)

Krogh M, Reid D (1996) Bycatch in the protective shark meshing programme off south-eastern New South Wales, Australia. Biol Conserv 77:219-226

* Lawson JM, Fordham SV, O'Malley MP, Davidson LNK and others (2017) Sympathy for the devil: a conservation strategy for devil and manta rays. Peer J 5:e3027

Marshall AD, Bennett MB (2010) Reproductive ecology of the reef manta ray Manta alfredi in southern Mozambique. J Fish Biol 77:169-190

* Mas F, Forselledo R, Domingo A (2015) Mobulid ray bycatch in longline fisheries in the south-western Atlantic Ocean. Mar Freshw Res 66:767-777

*Misty Paig-Tran EW, Summers AP (2014) Comparison of the structure and composition of the branchial filters in suspension feeding elasmobranchs. Anat Rec 297: 701-715

Notarbartolo-di-Sciara G (1987) A revisionary study of the genus Mobula Rafinesque, 1810 (Chondrichthyes, Mobulidae), with the description of a new species. Zool J Linn Soc 91:1-91 
Notarbartolo di Sciara G, Fernando D, Adnet S, Cappetta H, Jabado RW (2017) Devil rays (Chondrichthyes: Mobula) of the Arabian Seas, with a redescription of Mobula kuhlii (Valenciennes in Müller and Henle, 1841). Aquatic Conserv: Mar Freshw Ecosyst 27:197-218

Rohner CA, Pierce SJ, Marshall AD, Weeks SJ, Bennett MB, Richardson AJ (2013) Trends in sightings and environmental influences on a coastal aggregation of manta rays and whale sharks. Mar Ecol Prog Ser 482: 153-168

Rohner CA, Burgess KB, Rambahiniarison JM, Stewart JD, Ponzo A, Richardson AJ (2017) Mobulid rays feed on euphausiids in the Bohol Sea. R Soc Open Sci 4:161060

Sumpton WD, Taylor SM, Gribble NA, McPherson G, Ham T

Editorial responsibility: Eduardo Martins,

Vancouver, British Columbia, Canada
(2011) Gear selectivity of large-mesh nets and drumlines used to catch sharks in the Queensland shark control program. Afr J Mar Sci 33:37-43

*White WT, Giles J, Dharmadi, Potter IC (2006) Data on the bycatch fishery and reproductive biology of mobulid rays (Myliobatiformes) in Indonesia. Fish Res 82:65-73

White WT, Corrigan S, Yang L, Henderson AC, Bazinet al. Swofford DL, Naylor GJ (2017) Phylogeny of the manta and devilrays (Chondrichthyes: Mobulidae), with an updated taxonomic arrangement for the family. Zool J Linn Soc 20:1-26

* Yano K, Sato F, Takahashi T (1999) Observations of mating behavior of the manta ray, Manta birostris, at the Ogasawara Islands, Japan. Ichthyol Res 46:289-296

Submitted: August 16, 2017; Accepted: November 15, 2017 Proofs received from author(s): February 3, 2018 